\title{
Study of the Backhoe's Digging Modes at Rock Face Working-Out
}

\author{
Oleg Litvin ${ }^{1, *}$, Vladimir Makarov², Andrey Strelnikov², and Ekaterina Tyuleneva ${ }^{3}$ \\ ${ }^{1}$ T.F. Gorbachev Kuzbass State Technical University, Open Pit Mining Department, 650000 \\ Kemerovo, 28 Vesennya st., Russian Federation \\ ${ }^{2}$ CJSC Stroyservice, 650055 Kemerovo, 121 Kuznetsky Avenue, Russian Federation \\ ${ }^{3}$ T.F. Gorbachev Kuzbass State Technical University, Surveying and Geology Department, 650000 \\ Kemerovo, 28 Vesennya st., Russian Federation
}

\begin{abstract}
As is known from the classic works on open pit mining, the bench is a separately developed part of the rock layer, having the form of a step. It should also be noted that it is necessary to clearly differentiate the concepts of "bench height" and "height of the layer to be removed." The benches are often divided into subbenches, developed by different excavation equipment or by the same equipment both sequentially and simultaneously, but having transport routes that are uniform for the bench. As an example, an excavator stripping of the upper and lower subbenches with loading, respectively, at the level of the excavator and above this level, is usually given, that is, the transport route (road) passes through an intermediate platform bench located in the middle of its height. Therefore, the excavation layer of any height, which is, in fact, a part of the working bench, can be considered as an independent bench with all its attributes, but in order to avoid duplication of definitions, this paper suggests the name "extraction layer". When developing this element various digging modes can be applied. In this paper, we studied the main modes and selected the one that provides the highest performance.
\end{abstract}

\section{Introduction}

The use of rope shovels for separate extraction of coal seams has a significant drawback: the trajectory of the cutting edge of the bucket teeth does not always coincide with the direction of the coal-and-rock contact, which leads to the dividing of the bench into subbenches [1-3], complication of work process organization [4-7], decrease in excavator productivity [15], the appearance of additional rock volume, increased coal losses [8-11].

Nowadays backhoes, which, due to their design features, have an extended range of technological capabilities, have been used for mining coal-bearing zones on Kuzbass mines. In particular, lower digging (minimum bucket filling time); the trajectory of the cutting edge of the bucket teeth easily "adjusts" to the direction of the coal-and-rock contact, which reduces the loss of coal.

\footnotetext{
* Corresponding author: litvinoi@kuzstu.ru
} 
The equipment of the open pits with a new high-performance technology with a hydraulic drive makes it possible to move to a new level of technology $[16,17]$ that allows for better extraction of coal from the layers of the coal-bearing zones of the quarry fields.

The use of backhoes in the coal-bearing zone due to the wide variation in the thickness of coal seams and rock interbeds, folding and tectonic disturbance, which lead to frequent changes in dip angles, requires the adaptation of these machines to working conditions in the carbon-saturated zones.

\section{Materials and Methods}

Face block when it has been working-out by backhoes has parameters: height, width, angle of slope and berm width (Fig. 1).

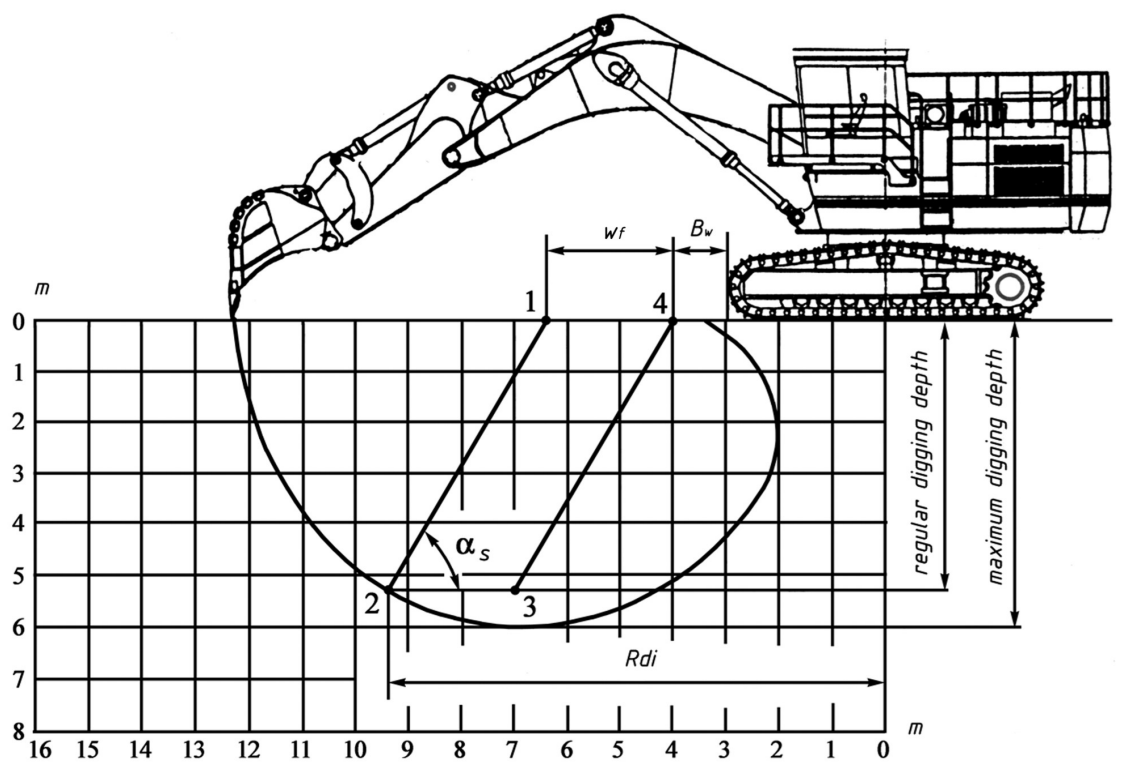

Fig. 1. Parameters of the backhoe's face.

For studying of these parameters there were 32 backhoe's faces examined. Bench height usually is equal 2 to 6 meters, berm width -1 to 2 meters, slope angle varying in more wide limits (Table 1).

Table 1. Angles of slope $\left(\alpha_{\mathrm{s}}\right)$ and berm width $\left(B_{\mathrm{w}}\right)$

\begin{tabular}{|l|c|c|}
\hline \multicolumn{1}{|c|}{ Type of excavated material } & $\begin{array}{c}\text { Angle of slope } \boldsymbol{\alpha}_{\mathrm{s}}, \\
\text { degrees }\end{array}$ & $\begin{array}{c}\text { Berm width } \\
\boldsymbol{B}_{\mathrm{w}} \text {, meters }\end{array}$ \\
\hline Massive coal & $60 \div 70$ & $1 \div 1,5$ \\
\hline Blasted (disintegrated) coal & $37 \div 45$ & $1 \div 1,5$ \\
\hline Rock massive & $60 \div 65$ & $1 \div 1,2$ \\
\hline Disintegrated rock & 37 & $1 \div 1,2$ \\
\hline
\end{tabular}


As a rule, the height of the bench in the coalless and coal-bearing zones of the open pit coincide, and the height of the bench in the coal-bearing zone is of subordinate importance. According to the projects of new mining enterprises, as well as projects of technical reequipment of existing mining enterprises, the height of the bench in the coalless zone is assumed to be equal to 10,12 or 15 meters. It corresponds to the parameters of the excavation equipment used in this zone (most often there are rope shovels, both domestic and foreign). It is highly inexpedient to use a lower bench height for such equipment because of the impossibility of filling the excavator bucket in one digging cycle and, as a result, due to a significant reduction in technical (effective) performance.

Another picture is observed when determining the height of the excavation layer for backhoes. Here it makes sense to refer to the latest works of Kuzbass scientists, for example [12-14]. In that articles attempted to establish a rational thickness of the excavation layer when installing dump trucks below the level of an excavator. The rational thickness of the layer, with the lower installation of the dump truck and its installation at the loading level differs by $25-50 \%$, and less thickness is determined in the second case. This is because with the lower installation of the dump truck, the height of the excavation layer can be assumed to be almost equal to the height of the dump truck, taking into account the safe clearance between the bottom of the bucket and the dump truck body (its walls), and when installed at the level of excavator standing, there is a significant decrease in the effective performance of the excavator with increasing layer's thickness.

The trajectory of the excavator bucket (or excavator working cycle) when operating with lower digging in general can be divided into components (elements): lowering the bucket down; filling the bucket (moving upwards); lifting the bucket from the bottom and raising it to the level of unloading; proper unloading; return to the starting position.

These elements do not take into account the rotation of the excavator body on the platform, i.e. this is a kind of projection of the movement of the working equipment of an excavator on a conditional plane passing through the axis of rotation of the excavator and the point of contact between the teeth of the bucket and the face.

\section{Results}

According to the actual observations and measurements of the parameters of the components of the excavator cycle, it is noted that the drivers with high qualifications combine two stages, carrying out at the same time not only lifting / lowering the bucket, but also turning around the axis of the excavator. This reduces the overall cycle time and, consequently, increases the productivity of the excavator. According to field observations on Kuzbass open pits, the excavator's maximum performance when operating with lower digging and bottom loading is ensured at the height of the bottom (thickness of the excavation layer) equal to the height of the dump truck, taking into account the safe clearance. In such conditions, the minimum angle of rotation of the excavator for unloading is in the range of $25-35^{\circ}$.

When loading at the level of standing, they strive to ensure the performance of the excavator, as close as possible to that discussed above. Equalizing them is unrealistic because of the longer cycle time, which cannot be reduced for objective reasons. To unload the excavator, it is necessary to raise the bucket not only from the face bottom to the level of the standing of the excavator, but also to the level of loading into the adjacent dump truck. According to field measurements, the cycle time is increased by $20-35 \%$. The height of the excavation layer in this case takes the minimum value sufficient for the bucket filling condition for one digging cycle. This value is equal to 2-3 $\mathrm{m}$ for different manufacturers and models of backhoes. 
In this article, work with bottom digging and bottom loading will be considered as the most favorable mode to ensure the highest performance of the excavator. Other modes of operation and calculations for them will be noted separately.

The excavation of rock from the face when digging by various shovel runners is carried out according to two schemes: removal of layers from top to bottom or from bottom to top.

When working from bottom to top occurs the collapse of a part of the rock, which, when excavated, makes it easier to introduce a bucket. It occurs especially when developing disintegrated rock. Due to the uncertainty of the priority of these two schemes, the task was set to study these modes of operation and recommend a rational one.

To solve this problem, it was necessary to determine the number of excavator cycles for the development of a face, measured in the study by the number of layers of the excavation $\mathrm{n}_{\mathrm{ls}}$. The number of layers was determined by dividing the bench height by the layer height.

Extraction layer's parameters (Fig. 2$)$ are: height $\left(h_{\text {layer }}\right)$, width ( $\left.w_{\text {layer }}\right)$ and length that is equal to width of the bucket $\left(w_{\mathrm{b}}\right)$.

Also, by observing the excavator's working process in the face, it was established that when the bucket is filled, it is embedded in the rock for the entire length $\left(l_{b}\right)$. So, width of the face $\left(w_{\mathrm{f}}\right)$ got approximately equal to length of the bucket $\left(l_{\mathrm{b}}\right)$.

To determine the height of the layer, a simulation was performed to determine the volume of rock depending on the passport parameters of the bucket (Fig. 3).

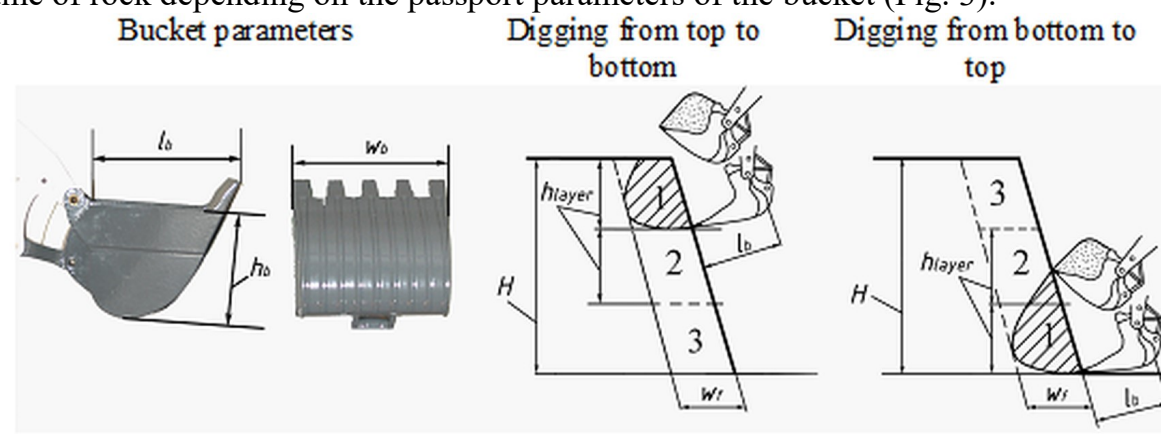

Fig. 2. Extraction layer's height and its quantity estimation.

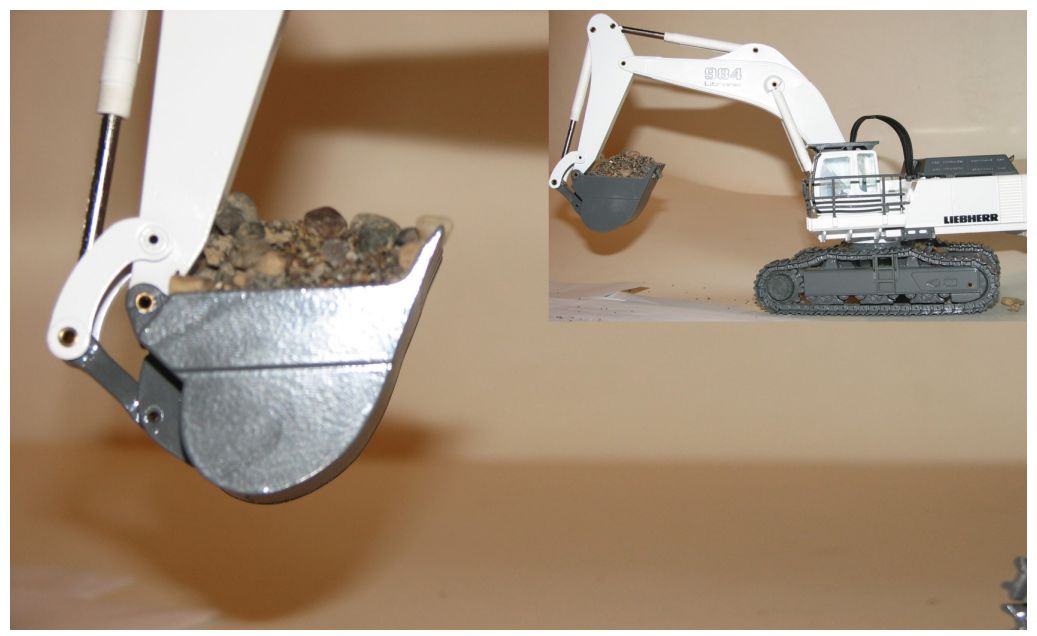

Fig. 3. Bucket fill modeling. 
Extraction layer volume, $\mathrm{m}^{3}$ :

$$
V_{\text {layer }}=h_{\text {layer }} \cdot l_{b} \cdot w_{b} \text {. }
$$

Table 2. Height ( $h_{\text {layer }}$ ) and number ( $\left.n_{\text {layer }}\right)$ of extraction layers at mining by excavators with different buckets capacity.

\begin{tabular}{|c|c|c|c|c|c|c|}
\hline \multirow{2}{*}{ Parameters } & \multicolumn{6}{|c|}{ Bucket capacity $€, \mathbf{m}^{3}$} \\
\hline & 3.1 & 5.1 & 7.0 & 10.2 & 11.0 & 13.0 \\
\hline$l_{\mathrm{b}}, \mathrm{m}$ & 2.6 & 2.4 & 2.4 & 3.65 & 3.65 & 3.5 \\
\hline$w_{\mathrm{b}}, \mathrm{m}$ & 1.55 & 2.4 & 3.0 & 2.8 & 2.9 & 3.15 \\
\hline$h \mathrm{~b}, \mathrm{~m}$ & 2.1 & 2.25 & 2.6 & 2.9 & 2.9 & 2.6 \\
\hline$h_{\text {layer, }} \mathrm{m}$ & 1.14 & 1.21 & 1.4 & 1.57 & 1.57 & 1.4 \\
\hline \multirow{8}{*}{$n$ layer } & \multicolumn{6}{|c|}{ Bench height $H=2.5 \mathrm{~m}$} \\
\hline & 2 & 2 & 2 & 2 & 2 & 2 \\
\hline & \multicolumn{6}{|c|}{ Bench height $H=3 \mathrm{~m}$} \\
\hline & 3 & 3 & 2 & 2 & 2 & 2 \\
\hline & \multicolumn{6}{|c|}{ Bench height $H=3.5 \mathrm{~m}$} \\
\hline & 3 & 3 & 3 & 2 & 2 & 3 \\
\hline & \multicolumn{6}{|c|}{ Bench height $H=4 \mathrm{~m}$} \\
\hline & 4 & 4 & 4 & 4 & 3 & 3 \\
\hline
\end{tabular}

Conditions: $V_{\text {layer }} \cdot C_{r l b}=V_{b}$,

where $V_{\mathrm{b}}$ - volume of rock in the bucket, $\mathrm{m}^{3} ; C_{\mathrm{rlb}}$ - coefficient of rock loosening in the bucket (depends on the type of the developed rock).

Volume of rock in the bucket, $\mathrm{m}^{3}$,

$$
h_{\text {layer }}=\frac{V_{b} \cdot C_{r l b}}{l_{b} \cdot w_{b}} .
$$

$$
V_{b}=\bar{C}_{v o l} \cdot l_{b} \cdot w_{b} \cdot h_{b},
$$

where $\bar{C}_{v o l}$ - statistical value of the correction factor in determining the volume of rock in the bucket:

$$
\bar{C}_{v o l}=\frac{\bar{V}_{b}}{l_{b} \cdot w_{b} \cdot h_{b}}=0.76 ; \quad h_{\text {layer }}=\frac{\bar{C}_{v o l} \cdot l_{b} \cdot w_{b} \cdot h_{b}}{l_{b} \cdot w_{b} \cdot C_{r l b}}=\frac{\bar{C}_{v o l} \cdot h_{b}}{C_{r l b}}
$$

Specifically, when modeling the value of the coefficient of proportionality $\bar{C}_{v o l}$ was studied. Experimentally by 20 measurements, its statistical value $\bar{C}_{v o l}=0.76$ was established. This value is correct for Liebherr R984C excavator, which was assigned as a primary model object.

Thus, for engineering calculations, a simple formula for determining the height of the layer is obtained:

$$
h_{\text {layer }}=\bar{C}_{v o l} \cdot \frac{h_{b}}{C_{r l b}} \text {. }
$$




\section{Conclusions}

It has been established that the number of excavation layers or the number of digging cycles when developing a face with a height of benches of $2.5-6 \mathrm{~m}$ is $2-5$ for buckets with a capacity of $3-13 \mathrm{~m}^{3}$. Under field conditions, for the obtained values of the number of cycles in the Krasnobrodsky open-pit mine, when operating the Liebherr R-984C excavator with a $7.2 \mathrm{~m}^{3}$ bucket, time-keeping observations were made from the top-down and bottom-up modes.

Also it has been established that the cycle time of an excavator is longer when working from bottom to top than from top to bottom. This is explained by the fact that when digging from the bottom upwards with the collapse of the rock, it is necessary perform digging during further cycles from a greater depth, on which additional time is spent.

It can be used the bottom-up digging mode when excavating local volumes of the face, for example, when separate extraction of coal and rock, etc.

Thus, of the two possible modes of digging with the excavation of rock layers in the face - from top to bottom and from bottom to top - rational is top to bottom, providing an increase in effective (hourly) performance by $11-12 \%$.

\section{References}

1. P. P. Bhaveshkumar, J. M. Prajapati, International Journal of Mechanisms and Robotic Systems, 1:4, 261-282 (2013)

2. M. Cehlár, Z. Šimková, Economics and Innovation Management, 1, 52-65 (2017)

3. M. Cehlár, P. Rybár, J. Mihók, and J. Engel, Journal of mining and geotechnical engineering, 1:4, 4-23 (2019)

4. D. Hrehová, M. Cehlár, P. Rybár, N. Mitterpachová, Proceedings of 12th International Multidisciplinary Scientific GeoConference SGEM2012, 675-682 (2012)

5. M. Hummel, Journal of Mining Science, 48:1, 146-153 (2012)

6. B. N. Lokhanov, Y.A. Zakharov, M.M. Bereznyak, A.V. Kalinin, Soviet Mining, 3:5, 523-527 (1967)

7. A. R. Mattis, V.I. Cheskidov, V.N. Labutin, Soviet Mining, 48:2, 329-338 (2012)

8. V. M. Matushenko, Soviet Mining, 11:5, 576-578 (1975)

9. I. A. Mironenko, S.I. Protasov, Journal of mining and geotechnical engineering, 1:4, 24-34 (2019)

10. A. Prakash, V. Mallika, S.R. Murthy, K.B. Singh, International Journal of Mining Science and Technology, 23:1, 33-40 (2013)

11. B. Scott, P.G. Ranjith, S.K. Choi, K. Manoj, Journal of Mining Science, 46:3, 280-297 (2010)

12. M. A. Tyulenev, S.A. Zhironkin, O.I. Litvin, E.A. Tyuleneva, O.V. Zhironkina, S.O. Markov, Geotechnical and Geological Engineering, 35:5, 2065-2077 (2017)

13. M. Tyulenev, O. Litvin, M. Cehlár, S. Zhironkin, M. Gasanov, Acta Montanistica Slovaca, 22:3, 296-302 (2017)

14. E. A. Tyuleneva, Yu.V. Lesin, Ya.O. Litvin, Journal of mining and geotechnical engineering, 1:4, 35-49, (2019)

15. N. Demirel, S. Frimpong, Reclamation and Environment, 23:1, 4-20 (2009)

16. K. Hino, Quarterly of the Colorado School of Mines, 5, 3 (1956)

17. V. Golik, Yu. Dmitrak, E3S Web Conf., 21, 01018 (2017) 